\title{
Research on the Problems of Transition from Three- and-two-year Intermediate to Advanced Vocational Education under New Normal State and Its Countermeasures
}

\author{
Taking the Applied Electronic Technology Major in Underdeveloped Areas as an Example*
}

\author{
Huijing Chen \\ Shanwei Polytechnic \\ Shanwei, China 516600
}

\author{
Jiazhu Lin \\ Shanwei Polytechnic \\ Shanwei, China 516600
}

\begin{abstract}
Taking the applied electronic technology major in underdeveloped areas as an example, this paper expounds the significance of transition from three-and-two-year intermediate to advanced vocational education under new normal state, analyzes the major problems in the education currently, and puts forward the corresponding countermeasures to solve them from propaganda of recruiting students, constructing the professional standards by seeking common ground while reserving differences and developing curriculum standards after the past for the education.
\end{abstract}

Keywords-new normal; underdeveloped areas; applied electronic technology major; transition from intermediate to advanced vocational education

\section{INTRODUCTION}

The "Decision on Accelerating the Development of Modern Vocational Education" (Guofa [2014] 19)clearly stated that "Accelerating the construction of a modern vocational education system, deepening the integration of production and education, school-enterprise cooperation, and training hundreds of millions of highly qualified personnel and technology skilled talents," By 2020, we will form a modern vocational education system with Chinese characteristics and world-class standard which meets the needs of social development, deeply integrates

*Fund Project: 2014 Guangdong Provincial Advanced Vocational and Technical Education Research Project "Based on the Perspective of Small and Medium-sized Enterprises the Problems and Countermeasures in Applied Electronic Technology Major in transition from Intermediate to Advanced Vocational Education";2015 Guangdong Advanced Vocational Education Teaching Reform Project at the Background of "Made in China 2025" Research and Practice of Advanced Vocational Curriculum "PCB Design and Production" Reform in transition from Intermediate to Advanced Vocational Education(No.GDJG2015247); Characteristic Specialty Construction Project of Applied Electronic Technology in Quality Engineering Project of Shanwei Vocational Technical College in 2015 (number:swzytszy15005);2017 Guangdong Provincial Advanced Vocational Education Teaching Quality Assurance Work Steering Committee Teaching Reform Project "Research of Building Quality Guarantee System of Training Talents in Applied Electronic Technology Majors in transition from Intermediate to Advanced Vocational Education" (No.JXZB33) production and education, connects intermediate and advanced vocational education, communicates vocational education and general education and reflects the concept of lifelong education."[1] Under the guidance of the concept of lifelong education, it is the need for social development that intermediate vocational school graduates receive further education. To make a good connection between intermediate and advanced vocational education is an effective way to rapidly develop vocational education. At present, the connection in our country is still at the initial stage. Therefore, it is of urgent and realistic significance to study it.

II. THE SIGNIFICANCE OF CARRYING OUT THE WORK OF TRANSITION FROM THREE-AND-TWO-YEAR INTERMEDIATE TO ADVANCED VOCATIONAL EDUCATION UNDER NEW NORMAL STATE

The gross output value of Guangdong's electronic information industry accounts for about one-third of the country's total output value, ranking first in the country for 19 consecutive years. It has become an important electronic information industry manufacturing base in the world. "the Thirteenth Five-Year Plan Outline for National Economic and Social Development of Guangdong Province" proposed that "Guangzhou and Shenzhen as the core, focus on electronic information technology, biotechnology and others, further expand chip design, equipment, module manufacturing, downstream terminal and application development industry chain, to create a number of internationally competitive electronic information industry clusters on the east bank of Pearl River, and to lead the electronic information industry in Heyuan, Shanwei and others to accelerate development."[2] "the Thirteenth Five-Year Plan Outline for National Economic and Social Development of Shanwei City" puts forward "to enlarge and strengthen the new generation of information technology industry. Take trust, Tencent, China Resources and others as a leader, accelerate the development of four new major information technology industries including new generation flat panel display, new electronic components, integrated circuits and cloud computing. Focus on promoting 
the construction of Hongcao Hi-tech Development Zone and $\mathrm{EFu}$ Information City, and integrate it into the electronics manufacturing industrial belt on the eastern shore of Pearl River to create the electronic information industry base of Guangdong Province.'[3] The development of Guangdong's electronic information industry is bound to drive Shanwei's electronic information industry development.

Under the old normal, the traditional electronic industries were mainly labor-intensive, and the jobs needed workers who were primary or intermediate skilled. Therefore, in the past few decades, cultivating intermediate vocational students could meet most of the electronic companies' requirements. Under the new normal, the electronic industry has transformed and upgraded, and electronic companies have put forward new demands for jobs - technology-intensive. With "Made in China 2025"putting forward and the advent of machine substitution, enterprises have put forward new requirements for electronic technology talents - not only to have the professional ability to adapt to the intelligent upgrade of production equipment, but also to have the ability to study new technologies and processes for life and adapt to job transfers.

With the transformation and upgrading of Shanwei's electronic information industry, there is a growing demand for high-quality technical and skilled personnel. But there is only one advanced and eight intermediate vocational colleges in Shanwei. The amount of advanced vocational graduates every year has been unable to meet regional companies' needs for talents. Finding a job is easy for intermediate vocational students, but career development is difficult for them. Therefore, intermediate vocational colleges also begin to face difficulties in recruiting students. Enrollment expansion in universities has also affected the source of students in advanced vocational colleges. The connecting of intermediate and advanced vocational colleges has enabled intermediate vocational students to have an opportunity to advance their academic qualifications and guaranteed the source of students in intermediate and advanced vocational colleges. So that can achieve a consistent development of vocational education and improve the quality of personnel.

Therefore, it is the common demand for the development of regional economy and vocational education to study intermediate to advanced vocational talent fostering mode which will adapt to the regional industrial development and to broaden the growth path for electronics talents of high quality in the region.

\section{The MAIN PRoblems EXISTING IN THE CONNECTING OF INTERMEDIATE AND ADVANCED VOCATIONAL EDUCATION}

\section{A. The Propaganda and Popularization of the Enrollment Mode of Three-and-two-year Intermediate to Advanced Vocational Education Is Insufficient}

In 2010, Guangdong Province initiated the independent enrollment pilot work of intermediate to advanced vocational education. In 2013, Shanwei Vocational Technical College carried out enrollment pilot work with the three intermediate colleges in the region for the first time in the applied electronic technology major. This is a new pilot enrollment model, it has not been popularized in the whole society. The propaganda is not enough, and the public does not know much about the mode of three-and-two-year intermediate to advanced vocational education. So the first pilot enrollment work didn't get ideal source of students.

\section{B. The Professional and Curriculum Standards of Intermediate to Advanced Vocational Education Have Not Been Unified}

Take the Applied Electronic Technology major in our department as an example. We started to carry out enrollment pilot work with several intermediate vocational technical colleges in Shanwei City, Lufeng, and Haifeng in Applied Electronic Technology major from 2013.The research work in intermediate to advanced vocational education is still in its infancy. There have not been unified professional and curriculum standards yet.

Because there is no professional and curriculum standard as a guide, intermediate and advanced vocational technical colleges are basically teaching according to the original curriculum system. The professional courses offered by the electronics majors in intermediate colleges mainly include electrician basics, electronic technology, single chip microcomputer technology, electronic product assembly, and electronic technology; while advanced colleges also mainly include circuit analysis, electronic technology, single-chip microcomputer technology and electronic technology.

The electronics majors of these vocational colleges are not the same major, there are applied electronics technology, electronic information engineering and rural electrification. There are different personnel training specifications and objectives in different majors. The development and teaching conditions of intermediate vocational colleges are inconsistent For example, the training conditions inside the school, the teaching staff, the practice base outside the school, etc. Therefore, the guarantee conditions for the integrated talent training mode of intermediate to advanced are also different. There are also differences in the curriculum systems that are built. Some courses may have the same name, but teaching contents and goals are different. As a result, even having learned the same professional course, students from different intermediate schools may have different levels in basics. And the curriculum in advanced vocational education may overlap with the teaching content of some intermediate schools, or not connect with the content of other intermediate schools. On the contrary, it failed to exert the learning advantage of original intermediate students in advanced education.

\section{THE COUNTERMEASURES OF THREE-AND-TWO-YEAR INTERMEDIATE TO ADVANCED VOCATIONAL EDUCATION}

Corresponding solutions have been proposed through practical exploration in order to solve the problems existing in three-and-two-year intermediate to advanced vocational education. 


\section{A. Disseminating More About the Enrollment Mode of Intermediate to Advanced Vocational Education}

Intermediate and advanced vocational schools jointly carry out the publicity of the enrollment mode in the region, and explain it at the intermediate enrollment site for students. So that parents and students attending intermediate schools can truly understand the common place between this mode and the college entrance examination enrollment. Let them know it is an effective way for intermediate vocational students to advance their academic qualifications. Through publicity in recent years, the society has got a preliminary understanding of intermediate to advanced vocational education mode. And the effectiveness is also obvious. The number of students majoring in intermediate to advanced vocational education mode in intermediate schools has increased significantly in the lately years.

\section{B. Constructing Professional Standards Seeking Common Ground While Reserving Differences}

The necessity of reserving differences - Taking the Applied Electronic Technology major in our department as an example.
We cooperated with several intermediate vocational schools in the region in electronics majors. The development of intermediate schools is inconsistent. There are both national demonstration schools and ordinary schools. Therefore, when making professional standards, it is necessary to fully consider the differences in teaching conditions of different schools such as training conditions inside schools, teaching staff and the practice base outside the school. And ensure that the standards can be well carried out.

The necessity of seeking common ground is to give full play to the teaching advantages of the enrollment mode of three-and-two-year intermediate to advanced vocational education, ensure that students in the transition examination for intermediate colleges have a common professional foundation before they enter advanced colleges, and they can effectively achieve convergence learning in intermediate to advanced education.

First of all, the analysis of jobs corresponded to intermediate and advanced vocation is shown in "Table I".

TABLE I. THE ANALYSIS OF JOBS CORRESPONDED TO INTERMEDIATE AND ADVANCED VOCATION

\begin{tabular}{|c|c|c|c|c|c|}
\hline Business group & \multicolumn{3}{|c|}{ Production } & Sales service & Research and development \\
\hline Intermediate post group & $\begin{array}{l}\text { Product assembly } \\
\text { Product module } \\
\text { debugging } \\
\text { Product module repair }\end{array}$ & $\begin{array}{l}\text { Product } \\
\text { testing and } \\
\text { inspection }\end{array}$ & $\begin{array}{l}\text { Production } \\
\text { equipment } \\
\text { operating }\end{array}$ & Seller & None \\
\hline $\begin{array}{l}\text { The relationship between intermediate and } \\
\text { advanced post group }\end{array}$ & \multicolumn{5}{|l|}{ Promotion } \\
\hline Advanced post group & $\begin{array}{l}\text { Product debugging } \\
\text { Product repair }\end{array}$ & $\begin{array}{l}\text { Uality } \\
\text { hspection } \\
\text { rocess } \\
\text { hanagement }\end{array}$ & $\begin{array}{l}\text { Production } \\
\text { equipment } \\
\text { service }\end{array}$ & $\begin{array}{l}\text { Marketing } \\
\text { engineer } \\
\text { Technical } \\
\text { support }\end{array}$ & Product R\&D assistant \\
\hline
\end{tabular}

Through the analysis of jobs oriented, a consensus has been reached among intermediate schools, advanced schools and enterprises, and a clear orientation is given to the personnel training objectives and levels of electronics majors in the intermediate and advanced vocational schools in the region.

Secondly, according to the task of corresponding job group, the professional abilities needed for jobs are analyzed, the list of knowledge and skills is formed, and curriculum system is restructured. Then we can form the curriculum architecture corresponding to intermediate and advanced schools including professional basic ability, special ability, comprehensive ability, and development ability.

According to the job requirements of companies, professional qualification certificates are also recommended for the corresponding grades. And in the evaluation plan for the transfer of intermediate to advanced vocational colleges, the qualification certificates that recommended for intermediate students to obtain are clearly classified and recommended.

The effective implementation of the professional standards for intermediate to advanced vocational education shall be ensured through the assessment plan for the transfer of intermediate to advanced education. The theoretical part of the transfer assessment mainly includes the students' professional basic ability and professional special ability, and the skill part assesses students' comprehensive ability. Intermediate schools may decide to expand the ability development courses according to the actual situation, so as to achieve the professional standards by seeking common ground while reserving differences.

\section{Develop Intermediate to Advanced Vocational Education Courses Diversifiedly After the Past}

Through the analysis of jobs corresponded to intermediate and advanced vocation, it can be clearly understood that the jobs of intermediate and advanced vocation belong to different levels in the same field. Therefore, the learning content and objectives of curriculum must be clearly divided into intermediate and advanced vocational education, so that we can inherit from the past and play advantages of learning professional courses.

Industry personnel know job requirements and assignments the best. Therefore, the curriculum development must fully rely on the strengths of companies, intermediate colleges and advanced vocational colleges. Such a curriculum can be both professional and educational. Take the "PCB design and production" course in intermediate to advanced vocational education as an example. In intermediate period, the 
requirement for the electronic CAD draftsman's professional qualification standards is intermediate. It requires that students master the drawing of simple schematic diagrams and be able to complete a simple PCB drawing; In advanced period, the requirement for the electronic CAD draftsman's professional qualification standards is advanced. Students are required not only to be able to draw schematic diagrams, single-layer and double-layer PCBs, but also to fully consider the production process, electrical characteristics and product structure when drawing PCBs.

Therefore, the curriculum's teaching content corresponding intermediate and advanced vocational not only considers the differences in professional competence levels, but also the students' half-year internships. If the positions engaged do not use PCB design content, the knowledge will possibly be forgotten by students. Therefore, the content design of course teaching is by no means a simple hierarchy, but a connection work that requires to inherit and develop.

\section{CONCLUSION}

After several years of exploration and practice, the applied electronic technology major in our department has achieved initial reforms in the convergence of intermediate and advanced vocational education, which has been recognized by regional enterprises, intermediate vocational students and their parents. In the first session of the three-and-two-year education the ratio of advanced vocational colleges was $83 \%$, and the second session was $90 \%$.In 2017, the first session of the three-two students participated in the "Challenge Cup" undergraduate extracurricular academic scientific and technological works competition in Guangdong Province and won the special and second prize. Students also participated in the 2017 Guangdong University student science and technology innovation training project "multi-function module Learning car."

\section{REFERENCES}

[1] State Council. Decision on Accelerating the Development of Modern Vocational Education [Z]. Guofa [2014] No.19.2014-05-02.

[2] Guangdong Provincial People's Government. Notice on Printing and Distributing the "Thirteenth Five-Year Plan Outline for the National Economy and Social Development of Guangdong Province" [Z].Yuefu [2016[35]:59

[3] Shanwei Municipal People's Government. Notice on Issuing the "Thirteenth Five-Year Plan for the National Economy and Social Development of Shanwei City" [Z]. Yanfu [2016] No. 27: 34

[4] Lu Guomin, Wang Yuxin. Curriculum Development and Practice in Intermediate to Advanced Vocational Education [J]. Vocational Education Forum, 2014(06).

[5] Liu Aiying. The policy appeal of Intermediate to Advanced Vocational Education[J].China Vocational and Technical Education,2014(11).

[6] Ji Shunyuan. Research on the Hierarchical Characteristics of Intermediate to Advanced Vocational Education [J].Guangdong Education,2013(09)

[7] Zou Yulan. The theoretical basis analysis and connotation study of Intermediate to Advanced Vocational Education[J].Guangdong Education,2013 (09).

[8] Liu Huiui. The key to Intermediate to Advanced Vocational Education lies in teaching students according to their aptitude[J]. Education and Occupation, 2014(13).
[9] Wang Lijuan. Problems and Countermeasures in Intermediate to Advanced Vocational Education[J]. Curriculum Education Research,2014(11). 